\title{
Work-up for Cushing syndrome
}

\section{Lisa-Ann Fraser MD, Stan Van Uum MD PhD}

Previously published at www.cmaj.ca

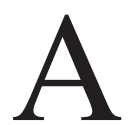

47-year-old woman was referred for assessment for Cushing syndrome. The patient's history included well-controlled type 2 diabetes mellitus, for which she took two hypoglycemic agents orally, and hypertension, for which she took three medications. On questioning, the patient reported that she did not take herbal or alternative supplements and had never taken steroids. She had no history of osteoporosis, depression, weight gain, irritability or fatigue.

On physical examination, the patient's weight was $67.7 \mathrm{~kg}$, and her body mass index was $26 \mathrm{~kg} / \mathrm{m}^{2}$. Her blood pressure was $128 / 80 \mathrm{~mm} \mathrm{Hg}$, and her heart rate was 68 beats/min. She had a very round face with prominent preauricular fat pads, as well as slight posterior cervical and supraclavicular fat pads (Figure 1). No proximal muscle weakness, striae, bruising, acne, hirsutism or thin skin were evident.

Two screening 24-hour urine collections for free cortisol were dramatically elevated at 2237 and 2736 (normal 120 384) $\mathrm{nmol} / \mathrm{d}$, suggesting Cushing syndrome. A fasting morning blood sample showed a cortisol level of 404 (normal 170720) $\mathrm{nmol} / \mathrm{L}$ and a borderline-high adrenocorticotropic hormone (ACTH) level of 10.6 (normal 0.0-10.1) pmol/L.

An overnight suppression test with high-dose $(8 \mathrm{mg})$ dexamethasone showed adequate suppression of cortisol $(37 \mathrm{nmol} / \mathrm{L})$

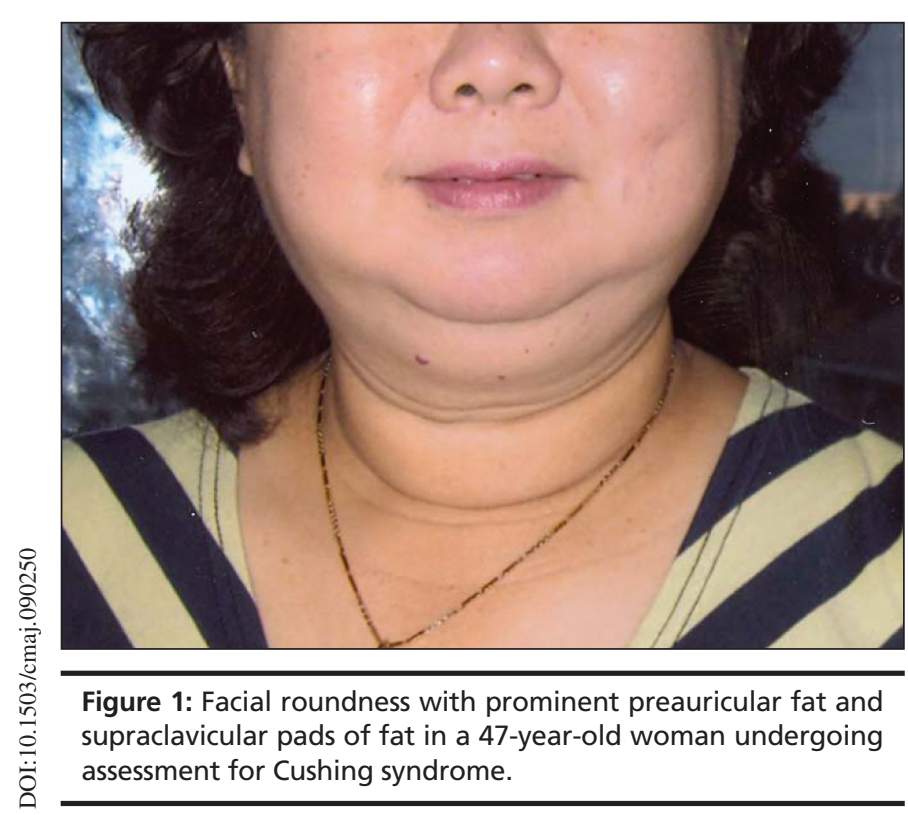

and $\mathrm{ACTH}(<2.0 \mathrm{pmol} / \mathrm{L})$. A magnetic resonance imaging scan of the sella was reported as inconclusive, showing a subtle abnormality within the right side of the pituitary gland.

\section{What is your diagnosis?}
a. Ectopic ACTH-secreting tumour
b. Cushing disease (pituitary adenoma)
c. Exogenous steroid use
d. Extreme stress
e. Adrenal cortisol-producing adenoma

\section{Discussion}

The most likely diagnosis is (b) Cushing disease (pituitary adenoma). The patient's borderline-high ACTH level points to an ACTH-dependent cause of Cushing syndrome. Overproduction of ACTH by a pituitary adenoma is known as Cushing disease and is one of several causes of Cushing syndrome - the constellation of a large group of signs and symptoms that reflect prolonged, inappropriately high exposure of tissue to glucocorticoids. The suppression of cortisol with high-dose dexamethasone and the results of magnetic resonance imaging point to a pituitary cause.

However, Cushing disease was not the correct diagnosis in this instance. Before discussing the reason, we will briefly review Cushing syndrome. For a thorough review, we refer readers to the evidence-based clinical practice guidelines of the Endocrine Society.

In normal physiology, various stressors induce the release of corticotropin-releasing hormone by the hypothalamus, resulting in release of ACTH by the pituitary. Cortisol and adrenal androgens (e.g., dehydroepiandrosterone sulfate) are in turn released by the adrenal glands. Cortisol has an inhibiting effect on the release of corticotropin-releasing hormone and ACTH that closes this negative feedback loop (Figure 2).

In endogenous Cushing syndrome of pituitary origin, this negative feedback system no longer functions appropriately. The result is an increase in the release of adrenal cortisol and

From the Department of Medicine, Schulich School of Medicine and Dentistry, University of Western Ontario, London, Ont.

CMAJ 2009. DOI:10.1503/cmaj.090250 


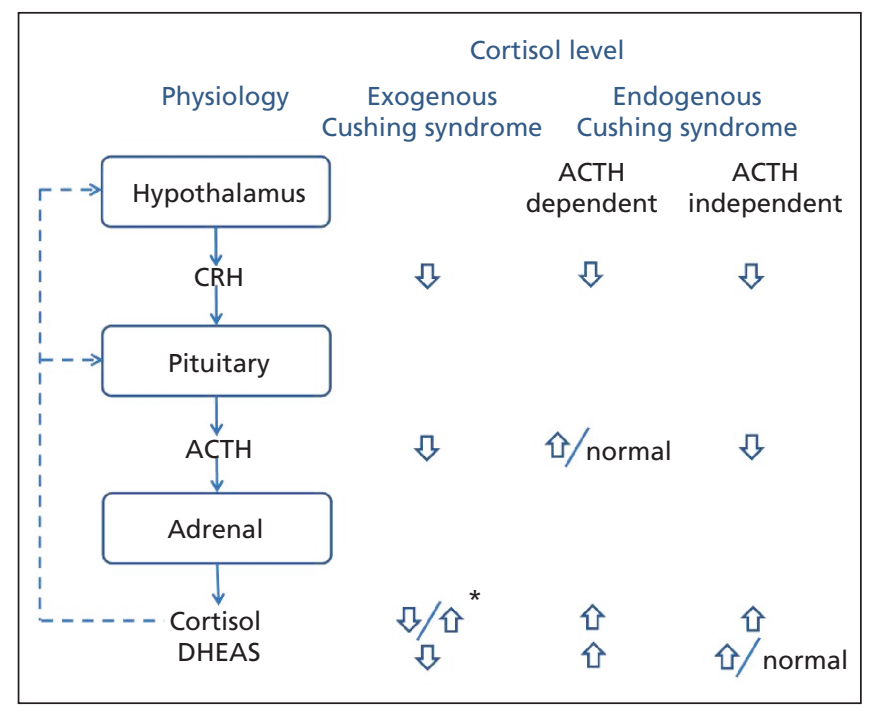

Figure 2: Regulation of the hypothalamic-pituitary-adrenal axis, and the changes in Cushing syndrome. Solid arrows show a stimulatory effect. Dashed arrows indicate an inhibitory effect. *Cortisol may be reduced or elevated depending on whether the exogenous glucocorticoid is cortisol or another glucocorticoid. Note: $\mathrm{ACTH}=$ adrenocorticotropic hormone, $\mathrm{CRH}=$ corticotropinreleasing hormone, DHEAS = dehydroepiandrosterone sulfate.

dehydroepiandrosterone sulfate, secondary to ongoing stimulation by ACTH. In adrenal Cushing syndrome, independent steroid production by the adrenal gland occurs, usually resulting in suppression of ACTH.

In exogenous Cushing syndrome, administration of an exogenous glucocorticoid suppresses the whole hypothalamus-pituitary-adrenal axis, resulting in low ACTH and dehydroepiandrosterone sulfate levels (Figure 2). Endogenous Cushing syndrome is uncommon, with an incidence of two to three per million per year. ${ }^{1}$ However, the diagnosis is important because the disease carries substantial morbidity and mortality. Elevated levels of cortisol may be associated with alcoholism, depression or obesity, making the diagnosis of Cushing syndrome more challenging with the co-occurrence of such conditions.

\section{When to suspect Cushing syndrome}

A complete history and physical examination are critical in determining the pretest likelihood of a diagnosis of Cushing syndrome. Patients present with a wide range of clinical features (Table 1), ${ }^{2}$ and no single symptom is necessary to the diagnosis. A high positive likelihood ratio (LR) for Cushing syndrome has been found in the presence of ecchymoses (LR 10.0-11.3), osteopenia or fracture (LR 8.0-13.8), proximal muscle weakness (LR 8.0-12.6) and hypertension (LR 4.355.29). ${ }^{3}$ Many of the signs and symptoms of Cushing syndrome are common in the general population. But if they occur at an unusual stage of life (e.g., hypertension or osteoporosis in a young person) or if multiple and progressive features are present (particularly worsening control of diabetes or hypertension), then a diagnosis of Cushing syndrome should be considered. ${ }^{2}$
The features of Cushing syndrome caused by exogenous steroids vary depending on the dose of the steroid used and the duration of use. Certain signs (e.g., cataracts, elevated intraocular pressure, necrosis of the femoral head, osteoporosis and pancreatitis) are more commonly associated with exogenous Cushing syndrome. ${ }^{4}$ Other signs, such as hirsutism and elevated dehydroepiandrosterone sulfate levels, are more suggestive of endogenous steroidogenesis.

\section{Exclusion of exogenous Cushing syndrome}

When Cushing syndrome is clinically suspected, the first step is to exclude intake of glucocorticoids, which is the most common cause of Cushing syndrome. Exogenous Cushing syndrome usually results from oral or parenteral therapy with high-dose glucocorticoids, but has also been reported to result from use of inhalational, ocular and dermatologic preparations containing glucocorticoids. Cushing syndrome caused by low doses of glucocorticoids taken together with medication that inhibits their metabolism has also been reported. An overview of steroid medications that can cause Cushing syndrome is shown in Table 2.

\section{Screening tests for endogenous Cushing syndrome}

After an exogenous cause has been excluded, diagnostic tests are used to determine if hypercortisolism is indeed present. Three screening tests are commonly used (Table 3 ). Testing at least twice for cortisol levels in urine and saliva is recommended. ${ }^{1}$ Abnormal test results should prompt referral to an endocrinologist for an assessment of the likelihood of Cushing syndrome.

If indicated, the endocrinologist will perform additional investigations to determine the exact cause of the hypersecretion of cortisol. Exogenous and endogenous causes will be

Table 1: Clinical features of Cushing syndrome

\begin{tabular}{lr}
\hline Feature & Proportion \\
\hline Obesity or weight gain & $95 \%$ \\
\hline Facial plethora & $90 \%$ \\
\hline Rounded face & $90 \%$ \\
\hline Decreased libido & $90 \%$ \\
\hline Thin skin & $85 \%$ \\
\hline Decreased linear growth & $70-80 \%$ \\
\hline Menstrual irregularity & $80 \%$ \\
\hline Hypertension & $75 \%$ \\
\hline Hirsutism & $75 \%$ \\
\hline Depression or emotional lability & $70 \%$ \\
\hline Bruising easily & $65 \%$ \\
\hline Glucose intolerance & $60 \%$ \\
\hline Weakness & $60 \%$ \\
\hline Osteopenia or fracture & $50 \%$ \\
\hline Nephrolithiasis & $50 \%$ \\
\hline
\end{tabular}

Reprinted from The Lancet, Vol. 367, Newell-Price J, Bertagna X, Grossman AB, et al. Cushing's syndrome, p. 1605-13, copyright (2006), with permission from Elsevier. ${ }^{2}$ 
differentiated first. When an endogenous cause is considered, further differentiation must be made between ACTHdependent causes (i.e., Cushing disease; ectopic production of $\mathrm{ACTH}$; ectopic production of corticotropin-releasing hormone) and ACTH-independent causes (i.e., adrenal adenoma or carcinoma) (Figure 2).

\section{What is the next step?}

a. Transsphenoidal resection of pituitary adenoma

b. Sampling of inferior petrosal sinuses for ACTH

c. Monitoring of symptoms at follow-up

d. Repeat of 24-hour urine test for free cortisol

e. Bilateral adrenal resection

In our patient, the urinary cortisol level was elevated to six to seven times the upper limit of the normal range, which is generally diagnostic for Cushing syndrome. Her morning ACTH was not suppressed, suggesting an ACTH-dependent form of Cushing syndrome rather than an adrenal adenoma. Further differentiation between a pituitary source of ACTH (i.e., Cushing disease) and ectopic ACTH is needed.
In the absence of conclusive magnetic resonance imaging of the pituitary, the next step would be sampling of the inferior petrosal veins for ACTH. However, we noted an apparent discrepancy between our patient's very high urinary excretion of cortisol and her clinical presentation. She lacked proximal myopathy, bruising or striae, and her blood pressure and diabetes were well controlled. At the patient's follow-up visit, therefore, we asked her specifically if she was using any creams, ointments or lotions. She then reported that she had been using a $2.5 \%$ hydrocortisone cream for over 20 years to treat itch on her arms, face, groin and vagina. She had not considered the cream to be a medication and so had not mentioned it before. The patient was instructed to discontinue its use. A 24-hour urine sample collected on the sixth and seventh days after discontinuation of the cream showed normal cortisol values of 225 and $153 \mathrm{nmol} / \mathrm{day}$. To rule out cyclical Cushing syndrome, urine collections were repeated one and two months later. The results remained normal.

Hydrocortisone cream can cause elevated excretion of urinary cortisol by either of two mechanisms. One involves the absorption of high-potency steroid creams and has been reported in infants when creams are used inappropriately for

Table 2: Causes of exogenous Cushing syndrome

\begin{tabular}{|c|c|}
\hline Route of administration of steroids & Examples of steroids \\
\hline Oral & $\begin{array}{l}\text { Prednisone, dexamethasone, methylprednisolone, megestrol acetate, }{ }^{1} \\
\text { supplements containing betamethasone, }{ }^{2} \text { some Chinese herbs (especially } \\
\text { those with anti-inflammatory properties) }{ }^{3}\end{array}$ \\
\hline Inhalation* & $\begin{array}{l}\text { Fluticasone when used with protease inhibitors in the treatment of HIV }{ }^{4} \\
\text { budesonide used with itraconazole in patients with cystic fibrosis }\end{array}$ \\
\hline Topicalt & Skin lightening cosmetic creams, ${ }^{6}$ ointments, clobetasol ${ }^{7}$ \\
\hline Ocular‡ & Glucocorticoid-containing eye drops ${ }^{8}$ \\
\hline Intradermal or intra-articular injection§ & Triamcinolone $e^{9,10}$ \\
\hline Nasal§ & Betamethasone ${ }^{11}$ \\
\hline Rectal & Betamethasone $^{12}$ \\
\hline Nerve block injection & Methylprednisone ${ }^{13}$ \\
\hline
\end{tabular}

Note: References for Table 2 are provided in Appendix 1, available at www.cmaj.ca/cgi/content/full/cmaj.090250/DC1.

*Especially in combination with medications that block steroid metabolism.

tCreams applied to genital area may contaminate urine samples and cause positive urinary free cortisol level without actually causing

hypercortisolism.

¥May occur with prolonged unsupervised use.

$\S$ Children are especially vulnerable.

Table 3: Tests used to screen for hypercortisolism

\begin{tabular}{|c|c|c|c|}
\hline Test & $\begin{array}{l}\text { Result suggestive of } \\
\text { Cushing syndrome }\end{array}$ & Principle of test & Remarks \\
\hline $\begin{array}{l}\text { 24-hour urinary excretion of } \\
\text { cortisol }\end{array}$ & $\begin{array}{l}\text { Cortisol level is above } \\
\text { upper limit of normal } \\
\text { range }\end{array}$ & $\begin{array}{l}\text { Confirms that cortisol } \\
\text { secretion is elevated }\end{array}$ & $\begin{array}{l}\text { Sensitivity to test is reduced if } \\
\text { creatinine clearance } \\
<60 \mathrm{~mL} / \text { min per } 1.73 \mathrm{~m}^{2}\end{array}$ \\
\hline $\begin{array}{l}\text { Overnight suppression of } \\
\text { dexamethasone } 1 \mathrm{mg}\end{array}$ & $\begin{array}{l}\text { Cortisol level > } 50 \mathrm{nmol} / \mathrm{L} \text { at } \\
\text { 8:00-9:00 am }\end{array}$ & $\begin{array}{l}\text { Shows loss of normal } \\
\text { sensitivity to negative } \\
\text { feedback }\end{array}$ & $\begin{array}{l}\text { Not accurate when cortisol- } \\
\text { binding globulin is altered (e.g., } \\
\text { by use of birth control pill) }\end{array}$ \\
\hline
\end{tabular}


diaper dermatitis, which results in Cushing syndrome and suppression of the hypothalamic-pituitary-adrenal axis in infants. ${ }^{5,6}$ This has also been reported in adults using skin lightening creams containing steroids. The second mechanism involves direct contamination of urine during urination. Falsely elevated urinary levels of free cortisol have been reported in two patients who used a combined antifungal and hydrocortisone $1 \%$ preparation for vaginal candidiasis. ${ }^{7}$ In our patient, this second mechanism was more likely, because absorption of hydrocortisone would have resulted in elevated systemic cortisol levels and convincing symptoms of Cushing syndrome. Intact negative feedback by the absorbed hydrocortisone acting on the secretion of pituitary ACTH would likely have resulted in a suppression of both ACTH and dehydroepiandrosterone sulfate (Figure 2).

This scenario shows how vaginal application of a topical cream containing hydrocortisone can cause falsely elevated urinary cortisol levels that mimic Cushing disease. Often such creams are used without a prescription. Patients may not regard topical lotions, creams and ointments as medicines or consider them relevant to an assessment for Cushing syndrome. Had the patient's use of a steroid cream not been discovered, suspicion would have been high for a pituitary adenoma, and she likely would have undergone petrosal vein sampling, which is an invasive procedure. It is important to enquire specifically about the patient's use of topical or other local therapies. Doing so could potentially prevent needless, costly testing and possible harm associated with invasive investigations or therapies.
This article has been peer reviewed.

Competing interests: None declared.

\section{REFERENCES}

1. Nieman LK, Biller BM, Findling JW, et al. The diagnosis of Cushing's syndrome: an Endocrine Society Clinical Practice Guideline. J Clin Endocrinol Metab 2008;93:1526-40.

2. Newell-Price J, Bertagna X, Grossman AB, et al. Cushing's syndrome. Lance 2006;367:1605-13

3. Hall JE, Nieman LK, editors. Handbook of diagnostic endocrinology: Cushing's syndrome. New York (NY): Humana Press; 2003. p. 67-84.

4. Kronenberg HM, Melmed S, Polonsky KS, et al. Williams textbook of endocrinology. 11th ed. Philadelphia (PA): Saunders Elsevier; 2008. p. 467.

5. Guven A, Gulumser O, Ozgen T. Cushing's syndrome and adrenocortical insufficiency caused by topical steroids: Misuse or abuse? J Pediatr Endocrinol Metab 2007;20:1173-82.

6. Ozon A. Cetinkaya S, Alikasifoglu A, et al. Inappropriate use of potent topical glucocroticoids in infants. J Pediatr Endocrinol Metab 2007;20:219-25.

7. Kelly CJ, Ogilvie A, Evans JR, et al. Raised cortisol excretion rate in urine and contamination by topical steroids. BMJ 2001;322:594.

CMAJ invites submissions to "What is your call?" Clinical details (including images) are presented on the first page along with a multiple-choice question about the diagnosis. The answer and a brief discussion of the condition follow on the second page. We specifically invite submissions illustrating common or important radiographic and electrocardiographic diagnoses of appeal to a general audience. We generally allow up to five references and require authors to obtain consent from the patient for publication of his or her story (form available at www.cmaj.ca/authors/checklist.shtml). Submit manuscripts online at http://mc.manuscriptcentral.com/cmaj.

\section{Change of address}

We require 6 to 8 weeks' notice to ensure uninterrupted service. Please send your current mailing label, new address and the effective date of change to:

\section{CMA Member Service Centre}

1870 Alta Vista Dr. Ottawa ON K1G 6 R7

tel $888855-2555$ or

$613731-8610 \times 2307$

fax $613236-8864$

cmamsc@cma.ca

\section{Changement d'adresse}

II nous faut de 6 à 8 semaines d'avis afin de vous assurer une livraison ininterrompue. Veuillez faire parvenir votre étiquette d'adresse actuelle, votre nouvelle adresse et la date de la prise d'effet du changement, à l'attention du

\section{Centre des services aux membres de l'AMC}

1870, prom. Alta Vista

tél 888 855-2555 ou

$613731-8610 \times 2307$

fax $613236-8864$

cmamsc@cma.ca

\section{ASSOCIATION MÉDICALE CANADIENNE \& ASSOCIATION

